\title{
Artificial and Fake Eggs: Dance of Death
}

\author{
S.M. Zahid Hosen, Swati Paul, Dibyajyoti Saha*
}

Department of Pharmacy, BGC Trust University Bangladesh, Chittagong

*Corresponding Author: saha.dibyajyoti@gmail.com

Copyright $(2013$ Horizon Research Publishing All rights reserved.

\begin{abstract}
In 21th century, the human being has gained the ability to make the clone of natural things and one of the most wonderful examples is fake egg production which is looked real as the original one. Fake egg or artificial egg is made by using various types of raw materials, colors and flavors. Normally eggs provide about six grams of protein-half of this protein is in the egg white. Most of the nutrients in eggs are found in yolk. But artificial eggs are full of chemicals, additives and auxiliary agents. So fake eggs contain no nutritional values compared to the real eggs. In China it was claimed in various news that fake eggs are sold in the local market because of money. The chemicals used for artificial eggs causes metabolic disorders, brain damage, liver disease, cancer and many other diseases. So the productions of fake eggs haven't any health benefit rather it's a chemical hazard. Generally the artificial creation of natural things doesn't blessing for human being.
\end{abstract}

Keywords Fake Eggs, Real Eggs, Chemical Hazard, Metabolic Disorder, Brain Damage, Cancer

\section{Introduction}

This treatise attempts to put the alarm on the use of artificial and fake eggs as surrogates of real eggs in certain countries due to the lack of nutritional value and the high content of additives and chemicals with potential harmful effect on humans. To inform the scientific community and general people about the bad practices in food industry and related potential challenges for health is of the highest relevance. Eggs are highly nutritious foods. One large egg provides about six grams of protein; about half of this protein is in the egg white. Egg white is considered an ideal protein-the one by which all others are measured because it contains all the essential amino acids in proper proportion for human nutrition. Of the total fat in eggs, more than half is the unsaturated variety. Eggs are a significant source of iron, riboflavin, folate and vitamins $\mathrm{B}_{12}, \mathrm{D}$, and $\mathrm{E}$. The iron in egg yolks, like the iron in meat, is highly bioavailable; egg yolks may therefore be valuable in the diets of individuals who may need more iron, such as infants [1]. An egg's contribution of vitamin D is noteworthy because the egg is one of the very few foods that supply this nutrient. About the only nutrient not found in an egg is vitamin C. Eggs are one of the best sources of a nutritionally important substance called choline; the other top sources are milk, liver, and peanuts. The human body manufactures its own choline, but it may not always be able to make enough of it to fully meet the body's needs. Therefore, dietary sources of choline may be necessary. Choline is also being investigated for possible beneficial effects on cognitive function [2]. Eggs add protein to a person's diet, as well as various other nutrients. Chicken eggs are the most commonly eaten eggs. They supply all essential amino acids for humans (a source of 'complete protein'), [3] and provide several vitamins and minerals, including retinol [4] (vitamin A), riboflavin (vitamin B2), folic acid (vitamin B9), vitamin B6, vitamin B12, choline, iron, calcium, phosphorus and potassium. Although not as abundant as red meats, eggs are a source of CoQ10 depending on how they are prepared [5]. All of the egg's vitamins A, D, and E are in the egg yolk. The egg is one of the few foods to naturally contain vitamin D. A large egg yolk contains approximately 60 Calories (250 kilojoules); the egg white contains about 15 Calories (60 kilojoules). A large yolk contains more than two-thirds of the recommended daily intake of $300 \mathrm{mg}$ of cholesterol (although one study indicates the human body may not absorb much cholesterol from eggs) [6]. The yolk makes up about $33 \%$ of the liquid weight of the egg. It contains all of the fat, slightly less than half of the protein, and most of the other nutrients. It also contains all of the choline, and one yolk contains approximately half of the recommended daily intake. Choline is an important nutrient for development of the brain, and is said to be important for pregnant and nursing women to ensure healthy fetal brain development [7]. The diet of the laying hens can greatly affect the nutritional quality of the eggs. For instance, chicken eggs that are especially high inomega 3 fatty acids are produced by feeding laying hens a diet containing polyunsaturated fats and kelp meal. Pasture-raised free-range hens which forage largely for their own food also tend to produce eggs with higher nutritional quality in having less cholesterol and fats while being several times higher in vitamins and omega 3 fatty acids than standard factory eggs [8]. Focusing on the protein and crude fat content, a 2010 USDA study determined there were no significant differences of these two 
macronutrients in consumer chicken eggs [9]. Cooked eggs are easier to digest,[10] as well as having a lower risk of salmonellosis [11].

\section{Food Guide Pyramid in Eggs}

In the Food Guide Pyramid, eggs are part of the group of protein rich foods, officially known as the "Meat, Poultry, Fish, Dry Beans, Eggs, and Nuts Group". The Pyramid calls for two to three servings from this group every day, for a total of five to seven ounces of meat or its equivalent. One egg can be substituted for one ounce of meat. One egg therefore counts as one-third to one-half of a meat group serving. Now this source of nutritional value is become fake in several countries like China and Malaysia. Fake egg is full of chemicals, the main ingredient calcium alginate, at most is a gel. Alum, gelatin etc are only as additives, auxiliary agents. There are national standards on the use of additives; the amount of them is clearly defined. In the artificial eggs they have become the major components; they are not beneficial to the human body. Artificial egg has little or no nutrition value compare with the real egg [12].

\section{Recommendations}

1. The National Academy of Sciences, which establishes the recommendations for nutrient intake in the U.S., says that $550 \mathrm{mg} /$ day and $425 \mathrm{mg} /$ day are adequate intakes of choline for men and women, respectively. Since a large egg contains $280 \mathrm{mg}$ of choline, it meets more than half of the daily recommendation.

2. In Spain is recommended 3-4 servings of egg per week.

\section{Anatomy and Characteristics of Real} Eggs

Air Cell

The larger end of the egg contains the air cell that forms when the contents of the egg cool down and contract after it is laid. Chicken eggs are graded according to the size of this air cell, measured during candling. A very fresh egg has a small air cell and receives a grade of AA. As the size of the air cell increases, and the quality of the egg decreases, the grade moves from AA to A to $\mathrm{B}$. This provides a way of testing the age of an egg: as the air cell increases in size, the egg becomes less dense and the larger end of the egg will rise to increasingly shallower depths when the egg is placed in a bowl of water. A very old egg will actually float in the water and should not be eaten[13].

\section{Egg Shell}

Egg shell color is caused by pigment deposition during egg formation in the oviduct and can vary according to species and breed, from the more common white or brown to pink or speckled blue-green. In general, chicken breeds with white ear lobes lay white eggs, whereas chickens with red ear lobes lay brown eggs.

\section{Egg White}

White is the common name for the clear liquid (also called the albumen or the glair/glaire) contained within an egg. In chickens it is formed from the layers of secretions of the anterior section of the hen's oviduct during the passage of the egg. ${ }^{[34]}$ It forms around either fertilizedor unfertilized yolks. The primary natural purpose of egg white is to protect the yolk and provide additional nutrition for the growth of the embryo.

Egg white consists primarily of about $90 \%$ water into which is dissolved $10 \%$ proteins (including albumins, mucoproteins, and globulins). Unlike the yolk, which is high in lipids(fats), egg white contains almost no fat, and the carbohydrate content is less than 1\%. Egg white has many uses in food, and many others, including the preparation of vaccines such as those for influenza[14].

\section{Egg Yolk}

The yolk in a newly laid egg is round and firm. As the yolk ages, it absorbs water from the albumen, which increases its size and causes it to stretch and weaken the vitelline membrane (the clear casing enclosing the yolk). The resulting effect is a flattened and enlarged yolk shape. Yolk color is dependent on the diet of the hen; if the diet contains yellow/orange plant pigments known as xanthophylls, then they are deposited in the yolk, coloring it. Lutein is the most abundant pigment in egg yolk. A colorless diet can produce an almost colorless yolk. Yolk color is, for example, enhanced if the diet includes products such as yellow corn and marigold petals. Egg yolk oil or egg oil is used for cosmetics and dermatology [15].

\section{Nutritional Value \& Acceptable Daily Intake (ADI) of Real Eggs}

The approximately nutritional value of whole \& hard boiled chicken egg (per 100 grams) is energy $647 \mathrm{kj}(155$ $\mathrm{kcal}$ ), carbohydrates $1.12 \mathrm{gm}$, fat $10.6 \mathrm{gm}$, protein $12.6 \mathrm{gm}$, tryptophan $0.153 \mathrm{gm}$, threonine $0.604 \mathrm{gm}$, isoleucine 0.686 $\mathrm{gm}$, leucine $1.075 \mathrm{gm}$, lysine $0.904 \mathrm{gm}$, methionine 0.392 gm, cystine $0.292 \mathrm{gm}$, phenylalanine $0.668 \mathrm{gm}$, tyrosine $0.513 \mathrm{gm}$, valine $0.767 \mathrm{gm}$, arginine $0.755 \mathrm{gm}$, histidine $0.298 \mathrm{gm}$, alanine $0.700 \mathrm{gm}$, aspartic acid $1.264 \mathrm{gm}$, glutamic acid $1.644 \mathrm{gm}$, glycine $0.423 \mathrm{gm}$, proline $0.501 \mathrm{gm}$, serine $0.936 \mathrm{gm}$, water $75 \mathrm{gm}$, vitamin A $19 \%$ and thiamine (vitamin B1) $0.066 \mathrm{mg}$ (6\%). Most of the nutrients in eggs are found in the yolk. The yolk contains all of the fat-soluble vitamins (A, D, and $\mathrm{E})$ and most of the other vitamins and minerals. Protein is found in both the white and the yolk.Eggs consist of approximately 9.5\% eggshell (including shell membrane), $63 \%$ albumin, and $27.5 \%$ yolk (Table 1 ). The main components are water $(75 \%)$, proteins $(12 \%)$, and lipids $(12 \%)$, as well as carbohydrates and minerals. The proteins are distributed throughout the egg, with the majority 
found in the egg yolk and egg white, and a small proportion in the eggshell and shell membrane. The lipids are found almost exclusively in the egg yolk, mainly in the form of lipoproteins. Several minerals have also been found in eggs, most of them in the eggshell. Carbohydrates are a minor egg component, present throughout the egg, as both free and conjugated forms, attached to proteins and lipids [16].

\section{Ingredients of Artificial Eggs}

Artificial or fake eggs have an unusual shape and do not smell or taste like real ones. Hence, the materials required to produce artificial eggs were cheap. The composition and purposes for preparing the artificial eggs are as follows (Table 2):

Table 1. Component of real eggs

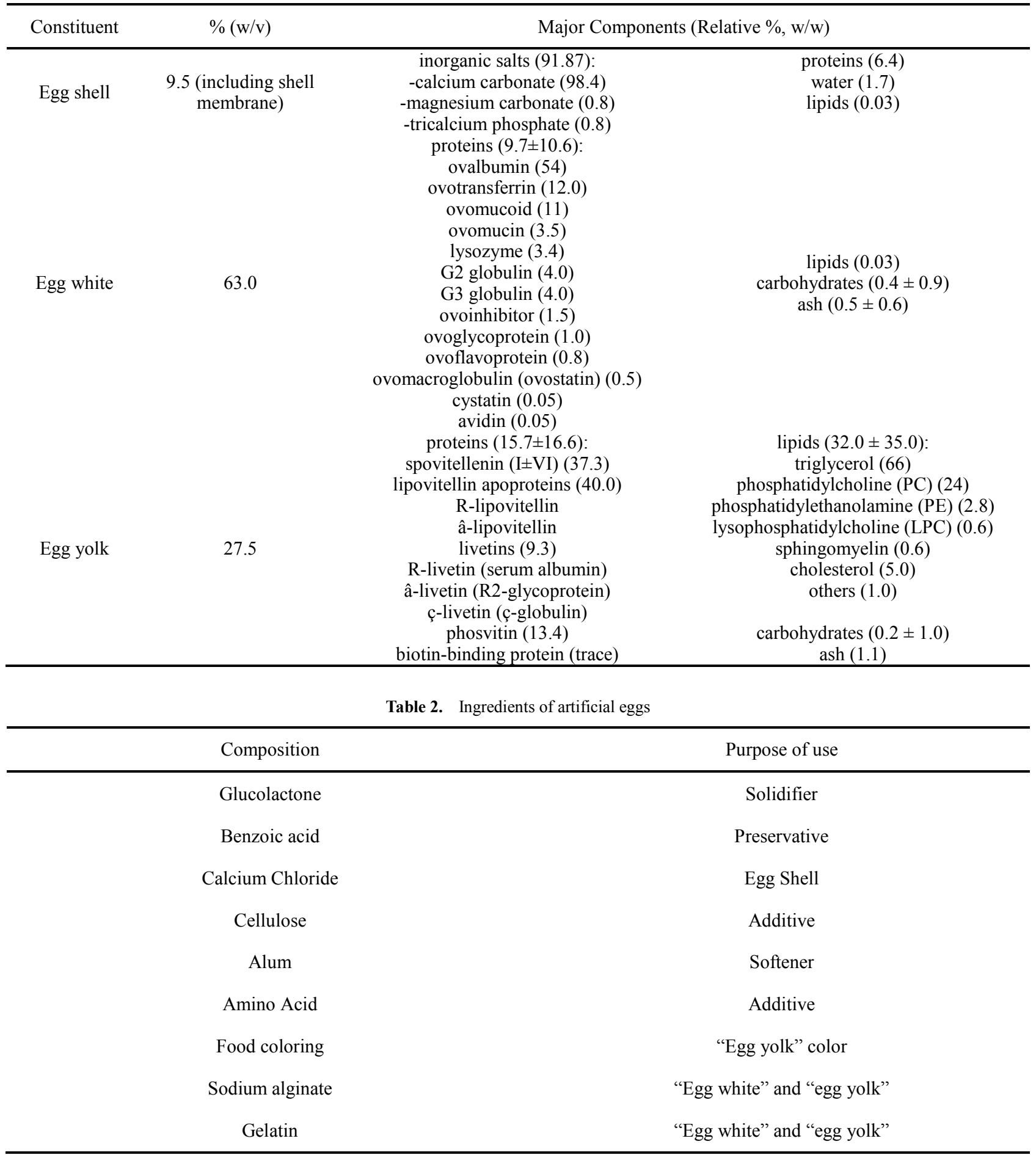




\section{Procedure of Preparing Artificial Eggs}

At first, sodium alginate which has been soaked in aqueous, adjusting the concentration, stirring evenly. Soon it will look slightly white and transparent, and should have the same viscosity as the real egg white. This is the main part of the "egg". Separate part of this liquid and then added a small amount of lemon yellow food coloring, by adjusting the color depth to look like the color of egg yolk. This is now the prototype of the "egg yolk". Then, pure the liquid into egg yolk shaped container, and promptly add calcium chloride dissolved in water. The outside of "Egg yolk" rapidly solidify and form a layer of transparent material. After one minute, "egg yolk" is formed. The solidified artificial egg yolk is put into artificial egg white, the egg's basic "content" is done. Finally the "egg yolk" and "egg white" are put into "egg shell" made of calcium carbonate. After seal the opening, an "egg" produced by raw material and chemicals is done. The entire production is less than 5 minutes, which is much more efficient than waiting for a hen to lay an egg [17].

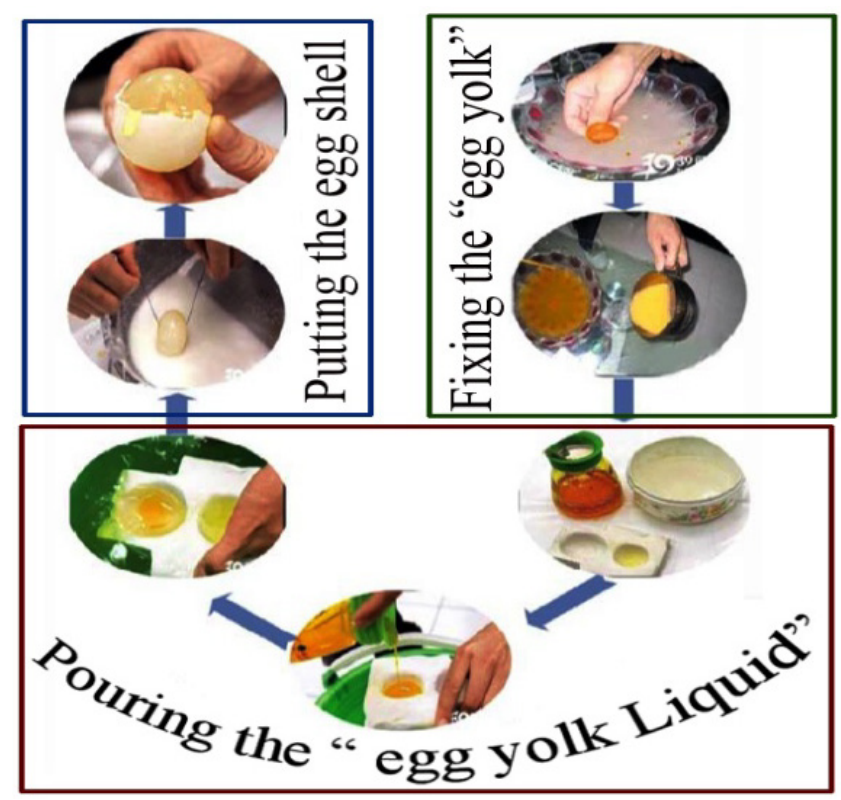

Figure 1. Procedure of preparing artificial eggs

\section{Toxicological and Side Effect of Artificial Eggs}

In UK etc. additives have an acceptable daily intake value (IDA) which is used as a security value for human intake without health risks. Thus, the side effects must be indicated based on the overcome of ADI values. The marking of egg shell is covered by Commission Regulation 1274/91. This states that 'Egg shell shall be marked in an indelible colour resistant to boiling. The product used must comply with the provisions in force in respect of colouring matters that may be used in foodstuffs intended for human consumption.' All colours listed in Schedule 1 may be used either to decorate egg shells or to stamp egg shells. Migration of colour from the shell to the egg would be negligible and, therefore, even those colours that are listed in Schedule 4, and restricted for certain uses, may be used for this purpose. For example erythrosine, which appears to be the colour most commonly used for this purpose, continues to be permitted.

Consumers as well as professional foodhandlers may be follow the safe procedures when handling and preparing eggs and food containing eggs. These procedures are of particular importance in countries (i.e. UK, Europe etc.) where there are cases of egg-borne salmonellosis caused by $S$. enteritidis. Sometimes calcium carbide is used in formulation of fake eggs. The calcium carbide which is hazardous, when ingested, inhaled skin irritant and even toxic to lungs and mucous membranes. Repeated and prolonged ingestion may damage certain organs. It produces acetylene and calcium hydroxide upon moisture contact. Acetylene a flammable gas that might contain the toxic impurities of hosphine and arsine. $\mathrm{Ca}(\mathrm{OH})_{2}-$ calcium hydroxide is irritating to respiratory system to skin and risk serious damage to eyes. The use of sodium benzoate-it forms carcinogen benzene when used in combination with potassium benzoate and ascorbic acid. Combination with certain food color is known to cause hyperactivity in children .The alum which is used as medicine but excess intake may cause irritation of mucous membrane of GIT, nausea and vomiting [18]. The artificial egg may be dangerous for human because it's made of different types of chemical compound. The composition of artificial eggs can cause following harm to human that may describe followed:

Table 3. Harmful effect of artificial eggs for human being

\begin{tabular}{cc}
\hline Composition & Side effects and harms \\
\hline Glucolactone & Metabolism disorder \\
Benzoic acid & Harmful to brain, nerve cell. May cause liver dieses, senile dementia. \\
Calcium Chloride & May cause nerve, liver diseases. May affect ability to produce blood. \\
Cellulose & Metabolism disorder \\
Alum & May cause nerve, liver dieses. May affect ability to produce blood. \\
Amino Acid & Metabolism disorder \\
Food coloring & Sick in the stomach \\
Sodium alginate & Increased Blood Pressure, Poor Bone Health, Congestive Heart Failure \\
Gelatin & Kidney damage \\
\hline
\end{tabular}




\section{Identification of Artificial Eggs}

Fake egg's shell is a little shinier than the real egg, but it is not very noticeable. When touch the fake egg by hand, it feels a little rougher than the real egg. Shake the fake egg will make some noises, because water overflows from the solid agent. Real egg smells a little like raw meat but fake egg has no smell like it. Tap the egg lightly. Real egg makes a more crisp sound than the fake egg. Shortly after opening the fake egg, egg yolk and egg white will melt together. This is because the egg yolk and egg white are made of the same raw materials. When frying a fake egg, the yolk will spread without being touched [17].

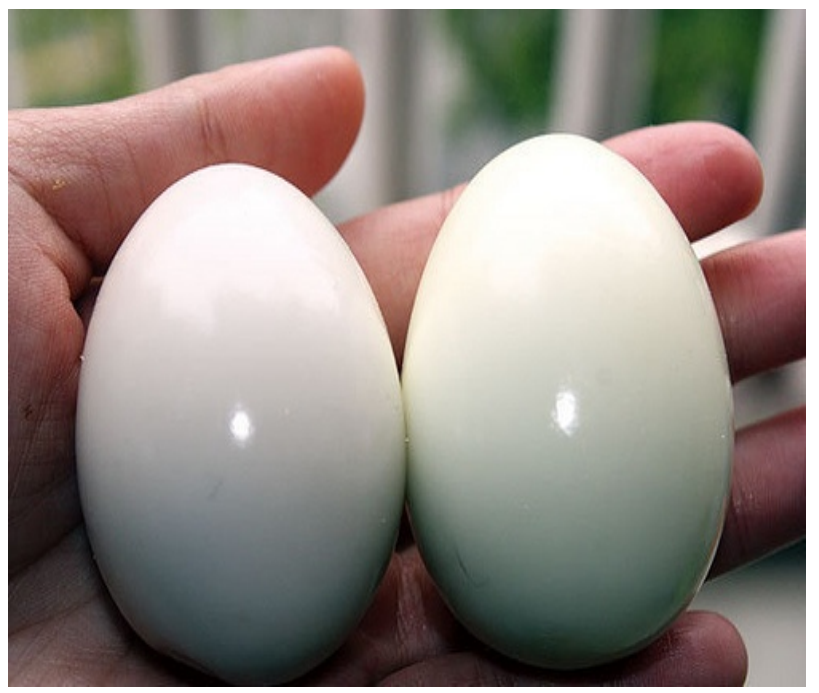

Figure 2. Identification between artificial and real eggs

\section{Conclusion}

Egg is beneficial for health. It helps to regulate the brain nervous system, cardiovascular system. New research shows that, moderate consumption of egg does not have a negative impact on cholesterol. It also promotes healthy hair, nails and prevents breast cancer, blood clots, stroke, and heart attack. But the fake egg which is dishonestly prepared by man is greatly harmful for a man's health [19]. The chemical constituents of fake egg are not beneficial to the human health. Artificial egg has little or no nutrition value compare with the real egg. It is harmful to brain, nerve cell, increased blood pressure, congestive heart failure, kidney damage and sick in stomach etc. The cost of preparation a fake egg is very low. We should concern the people about fake egg. We also should know the necessary steps to identify the fake egg and people should be informed. If the people concern about the fake egg one day country will be free from fake egg which is typically bad for human body.
[1] Makrides, M., Hawkes, J. S., Newmann, M. A., Gibson, R.A. (2002) 'Nutritional effect of including egg yolk in the weaning diet of breast-fed and formula-fed infants: a randomized controlled trial', Am J Clin. Nutr., 75:1084-1092.

[2] Hasler, C.M. (2000) 'The changing face of functional foods', J Am Coll Nutr., 19: 499S- 506S.

[3] "Food and Agriculture Organization article on eggs". Fao.org. Archived from the original on 2004-03-07. Retrieved 2010-01-10.

[4] Vitamin A, RAE Content of Selected Foods per Common Measure, sorted by nutrient content. United States Department of Agriculture (USDA). 2005. p. 4.

[5] "Natural Sources Of Coenzyme Q10 In Foods". Livestrong.Com. Retrieved 2013-06-11.

[6] "University Science article on eggs and cholesterol". Unisci.com. 2001-10-29. Retrieved 2010-01-10.

[7] "Eggs and fetal brain development". Pdrhealth.com. Retrieved 2010-01-10.[dead link]

[8] Long, Cheryl; Alterman, Tabitha (October/November 2007). Meet Real Free-Range Eggs. Mother Earth News.

[9] Jones, Deana; Musgrove, Michael; Anderson, K. E.; Thesmar, H. S. (2010). "Physical quality and composition of retail shell eggs". Poultry $\quad$ Science 89 (3): 582-587.doi:10.3382/ps.2009-00315. PMID 20181877.

[10] Evenepoel, P; Geypens B, Luypaerts A et al. (October 1998). "Digestibility of cooked and raw egg protein in humans as assessed by stable isotope techniques". The Journal of Nutrition 128 (10): 1716-1722. PMID 9772141.

[11] "Eggs - No Yolking Matter." Nutrition Action Health Letter, July/August 1997.

[12] Institute of Medicine and National Academy of Sciences (IOM). (1998). USA: "Dietary reference intakes for folate, thiamin, riboflavin, niacin, vitamin B12, panthothenic acid, biotin, and choline". National Academy Press, Washington DC.

[13] McGee, Harold (2004). McGee on Food and Cooking. Hodder and Stoughton. p. 70. ISBN 0-340-83149-9.

[14] Ornithology, Volume 1994 By Frank B. Gill p. 361.

[15] Shell eggs from farm to table. USDA Food Safety and Inspection Service, (2011).

[16] Mine, Y., Kovacs-nolan, J. and Phillips M. (2005) 'Advances in the Value of Eggs and Egg Components for Human Health', J. Agric. Food Chem. 53: 8421-8431.

[17] Hush, C. 'How to Identify Fake Chicken Eggs', China Science Symposium. April 24th, 2009.

[18] Marvin, K. (2011) 'Change log, site rules \& stuffs', available at 'http://www.foodrecap.net/safety/fake-egg-safety/.

[19] Andrew Bird - Andrew Bird \& The Mysterious Production of Eggs - Review - Stylus Magazine 